\title{
Quantification and accuracy of clinical [11C]-PiB PET/MRI: the effect of MR-based attenuation correction
}

\author{
Ian Law ${ }^{1 *}$, Flemming L Andersen ${ }^{1}$, Adam E Hansen ${ }^{1}$, Steen G Hasselbalch², Claes Ladefoged', Sune H Keller ${ }^{1}$, \\ Søren Holm', Liselotte Højgaard ${ }^{1}$ \\ From PSMR14: 3rd Conference in PET/MR and SPECT/MR \\ Kos Island, Greece. 19-21 May 2014
}

${ }^{1}$ The Department of Clinical Physiology, Nuclear Medicine and PET, Rigshospitalet, Denmark
The Dixon-Water-Fat segmentation (DWFS) method is a standard attenuation correction (AC) method in PET/MRI on the Siemens mMR and has demonstrated a systematic quantitative bias in [18F]-FDG-PET/MRI studies of the brain compared to PET/CT. The aim of this study was to evaluate the impact of DWFS-AC in a hybrid PET/MR scanner on regional and global quantitation of [11C]-PiB cerebral amyloid imaging of the brain and in the clinical reading.

Twenty-eight healthy volunteers, 6 with mild cognitive impairment (MCI), 4 with Alzheimers disease (AD), and 6 other dementia cases underwent a simultaneous PET/ MRI (Siemens mMR) acquisition 40 min pi of (170-709) MBq [11C]-PiB. A single 30 min frame was reconstructed twice (OSEM-3D, 21it 4 sub, $5 \mathrm{~mm}$ Gauss) with the only difference being the AC calculation. AC was performed using either the standard DWFS or a head low-dose CT scan acquired independently on the same day. Activity concentration $(\mathrm{Bq} / \mathrm{mL})$ was sampled on AC-PET from symmetrically delineated ROI's. Ratios of region-to-cerebellar grey matter (SUVr) were calculated. Amyloid uptake was considered abnormal at cortical SUVr $>1.5$ or increased amyloid uptake in two or more grey matter regions on visual evaluation.

The average activity concentration in all ROI's was biased by $-18 \%$ in DWFS-AC compared to CT-AC. Although the visual categorization of both, amyloid-positive $(\mathrm{n}=11)$ and -negative $(\mathrm{n}=33)$ scans was unaffected by DWFS-AC, 3 healthy subjects were quantitatively reclassified as amyloid positive. The SUVr values were overestimated by 0.11 in the caudate nuclei and 0.04 in lateral cortical ROI's in DWFS-AC compared to CT-AC.

The visual and quantitative consequences of MR-AC using DWFS in the brain with $[11 \mathrm{C}]-\mathrm{PiB}$ exhibit a noticeable radially variable bias. Although robust in visual evaluation, the quantitative diagnostic criteria (SUVr) using this biomarker with DWFS-AC may need to be modified.

Authors' details

${ }^{1}$ The Department of Clinical Physiology, Nuclear Medicine and PET, Rigshospitalet, Denmark. ${ }^{2}$ Memory Disorders Research Group, Rigshospitalet, Denmark.

\section{SpringerOpen ${ }^{\circ}$}

(C) 2014 Law et al; licensee Springer This is an Open Access article distributed under the terms of the Creative Commons Attribution License (http://creativecommons.org/licenses/by/4.0), which permits unrestricted use, distribution, and reproduction in any medium, provided the original work is properly cited. 
Cite this article as: Law et al:: Quantification and accuracy of clinical [11C]-PiB PET/MRI: the effect of MR-based attenuation correction. EJNMMI Physics 2014 1(Suppl 1):A69.

Submit your manuscript to a SpringerOpen ${ }^{\odot}$ journal and benefit from:

- Convenient online submission

- Rigorous peer review

- Immediate publication on acceptance

- Open access: articles freely available online

- High visibility within the field

- Retaining the copyright to your article

Submit your next manuscript at $\boldsymbol{\nabla}$ springeropen.com 